Jean-Louis Ska

\title{
The Exegesis of the Pentateuch
}

\section{Exegetical Studies and Basic Questions}

[Die Exegese des Pentateuch. Exegetische Studien und Grundfragen.]

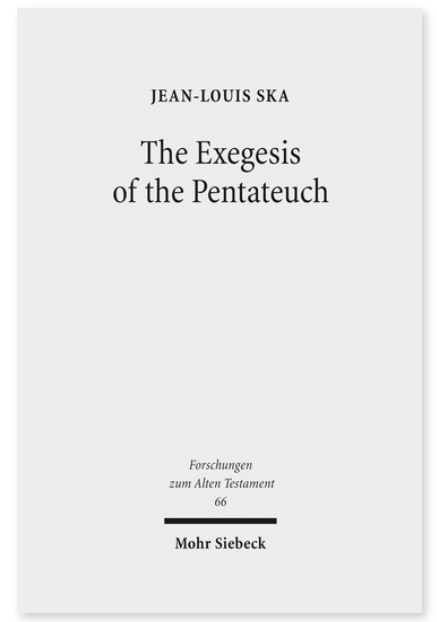

2009. XVI, 280 Seiten. FAT 66

ISBN 978-3-16-151107-3

DOI 10.1628/978-3-16-151107-3

eBook PDF 129,00€

ISBN 978-3-16-149905-0

Leinen $129,00 €$
Veröffentlicht auf Englisch.

Die hier gesammelten Aufsätze zeigen die Ergebnisse der jahrelangen Auseinandersetzung des Autors mit den Texten des Pentateuchs. Jean-Louis Ska nähert sich den Büchern immer wieder unter verschiedenen Blickwinkeln und mit Hilfe verschiedener Methoden. Bei den untersuchten Texten handelt es sich um die zentralen Passagen in den Debatten der letzten Jahre: Die Sintflut (Gen 6-9), die Berufung Abrahams (Gen 12,1-4), Gottes Verheißung an Abraham (Gen 15), die Einführung zum Sinai-Bund (Ex 19, 3-6) und der Bundesschluß (Ex 24, 9-11). Einige Leitbegriffe der Exegese werden ebenfalls analysiert, so unter anderem »Erzähler«, »narrative Analyse«, etc. Der Rückgriff auf die unterschiedlichsten Methoden der Analyse, seien sie diachron oder synchron, ist notwendig, um den Klang der alten biblischen Texte auch für die Gegenwart hörbar zu machen.

Jean-Louis Ska Born 1946; studies at the Facultés Notre-Dame de la Paix (Namur, Belgium), Sankt Georgen (Frankfurt, Germany), and the Pontifical Biblical Institute (Rome); 1984 doctorate in Sacred Scriptures; Professor of Old Testament Exegesis (Pentateuch) at the Pontifical Biblical Institute (Rome)

\section{Jetzt bestellen:}

https://mohrsiebeck.com/buch/the-exegesis-of-the-pentateuch-9783161511073?no_cache=1 order@mohrsiebeck.com

Telefon: +49 (0)7071-923-17

Telefax: $+49(0) 7071-51104$ 